\title{
The EfFects of Hybrid Pay Incentives on Work-Team Performance: A Longitudinal Study
}

\author{
Mbusi Dlamini and Margie Sutherland \\ Gordon Institute of Business Science, University of Pretoria \\ Merle Werbeloff \\ Wits School of Governance, University of the Witwatersrand \\ Accepted: May 2015
}

\begin{abstract}
Despite the widespread use of pay incentives to drive performance, few studies empirically demonstrate their long-term benefits within work-team settings in field studies; even fewer studies incorporate hybrid pay incentives in their design. This longitudinal field study explored the effects on individual work performance of allocating tellers to teams with supervisors who received hybrid pay incentives, where 60 per cent of their incentive was based on the individual performance of each of their team members and 40 per cent on their own performance. It was conducted on bulk-cash tellers working in 19 centres, using a time-series design. The results, derived from quantitative data collected from 82 individual tellers over 24 months, showed that hybrid pay incentives for supervisors of teams of tellers, some of whom were individually incentivised, were associated with significant increases in the volume, speed and accuracy of deposit processing by all the tellers. The findings empirically demonstrate the long term sustainability of improved performance associated with the introduction of hybrid pay incentive structures within work teams.
\end{abstract}

Key words: pay incentives, hybrid incentives, team work, interdependencies, longitudinal filed study

JEL: M52

\section{Introduction}

The competitiveness of a firm within a chosen market space depends significantly on how the firm best uses its resources (Coff \& Kryscynski, 2011; Shaw, Park \& Kim, 2013). For a large number of firms, a key resource to manage is labour (Crook, Todd, Combs, Woehr \& Ketchen, 2011); it is thus critical for firms to explore practices which support labour productivity improvements (Ployhart, Weekley \& Ramsey, 2009). In most firms, work is designed such that it is performed using collaborative effort amongst people, and also between people and machines (Messersmith, Patel, \& Lepak, 2011). In firms where labour is a key resource, collaboration happens between people working alone and people working in teams. Despite the prevalent assumption that all the people within the firm are working towards the firm's desired goals, individuals and groups within the firm cooperate and compete in different ways as they apply themselves to their tasks (Maruyama \& Elliot, 2012), resulting in different levels of output despite similar contexts. The challenge for organisations is to create the balance between collaborative and competitive tendencies for individuals within their firms. This is at the heart of how firms can optimise human resource efforts in support of the firm's objectives (Wagner, Humphrey, Meyer \& Hollenbeck, 2012). This study examines the effectiveness of combining team design and incentive methods to increase the performance levels of staff over time.

\section{Literature Review}

Teams have been described and classified using various heuristic frameworks (Cohen \& Bailey, 1997; Hollenbeck, Beersma \& Schouten, 2012; Mathieu, Tannenbaum, Donsbach \& Alliger, 2014). Cohen and Bailey described work-teams as “... continuing work units responsible for producing goods or providing services. Their membership is typically stable, usually full-time and 
well defined" (Cohen \& Bailey, 1997:242). Most of the units within work places which are controlled through some form of supervision would be classified as work teams. According to Banker, Field, Schroeder and Sinha (1996), in traditional work teams, members of the team engage in tasks allocated to them by the supervisor or manager, who has overall control over the allocation of resources and targets, and who controls the flow of work to team members. Teams possess boundaries (Cohen \& Bailey, 1997; Guzzo \& Dickson, 1996), which are circumscribed by their team membership definition. Teams consist of "... individuals who see themselves and who are seen by others as an intact social entity" (Cohen \& Bailey, 1997:241) and teams are “... individuals who share responsibility for outcomes" (Cohen \& Bailey, 1997:241).

Practitioners and scholars recognise the team as an important organisational work-form to deliver performance improvements within firms (Beersma, Hollenbeck, Humphrey, Moon \& Conlon, 2003; Mathieu, Maynard, Rapp \& Gilson, 2008). Teams in firms exist at many hierarchical levels and business units (LePine, Piccolo, Jackson, Mathieu \& Saul, 2008). Teams differ in focus, comprising work teams, management teams, project teams among others (Cohen \& Bailey, 1997). Studies on the impact of teams on performance include those at the team level, the organisational level within laboratory settings and in "live" working environments (Banker et al., 1996; Guzzo \& Dickson, 1996). Despite some scepticism on the effectiveness of teams on performance (Allen \& Hecht, 2004) the overriding usefulness of teams in improving performance, contingent on other local factors, is largely undisputed in practice or in the research carried out on teams (Devine, Clayton, Philips, Dunford, \& Melner, 1999; LePine et al., 2008; Wageman \& Baker, 1997).

Various studies and meta-reviews have focussed on the effects of pay incentives on performance improvements for teams and individuals (Barnes, Hollenbeck, Jundt, DeRue \& Harmon, 2011; Jenkins, Mitra, Gupta, \& Shaw, 1998; Mathieu et al., 2008). Some studies have looked at the effects of a combination of reward systems in different types of teams (Beersma et al., 2003). In general, the studies highlighted the positive influence of the judicious use of the combination of individual and team-based pay incentives on performance. The studies also highlighted the indirect relationships between pay incentives and performance - emphasising the role of intervening variables, such as motivation and goal setting. However, no research could be found in a longitudinal field setting to determine changes in individual performance levels over time after supervisors are incentivised, partially based on their individual team members' performance i.e. via hybrid incentives. This is the objective of this research.

Firms tend to structure financial incentives in the hope they will support their desired outcomes (Jenkins et al., 1998; Wagner et al., 2012). Part of the intention in the deliberate structuring of rewards by firms is to support the necessary level of interdependencies within and among teams, and among individuals (Jenkins, et al., 1998; Wageman, 1995; Wagner, et al., 2012). Despite the prevalence of work teams within organisations (Devine et al., 1999), extant literature shows a gap in studies on the combined effects of direct and hybrid pay incentives on team performance over time. In addition, studies which examine change in performance through time are lacking within the team literature (Bell \& Marentette, 2011; Ployhart \& Vandenberg, 2010; Stewart, 2010; Sonnentag, 2012). This study draws on the extant literature on cooperation and competition (e.g. Beersma et al., 2003; Deutsch, 1949), pay incentives and performance (Barnes et al., 2011; Jenkins et al., 1998) as foundations to examine the effects of both individual team-member pay incentives, and supervisor-level hybrid pay incentives in work-team performance over time.

According to the 2012-2013 Global Competitive Index "Sub-Saharan Africa as a whole lags behind the rest of the world in competitiveness, requiring efforts across many areas to place the region on a firmly sustainable growth and development path going forward" (World Economic Forum, 2012). In South Africa, a relatively high level of of labour use within production environments predominates; this dependence on labour is expected to continue, as a means of creating employment. Unionisation of labour in South Africa is very well developed (Vietor, 2007), and is supported by two pieces of legislation: the Labour Relations Act of 1995; and the Basic Conditions of Employment Act of 1997. Firms which operate within the South African 
environment and all firms which rely on labour productivity as a competitive advantage, need to continue to find productivity improvement mechanisms if they are to be sustainable. The use of pay incentives within teams is one of these options.

The literature on interdependent work teams and the literature on pay incentives suggest that specific combinations of these two variables result in predictable performance output and improvement (Barnes et al., 2011; Cohen \& Bailey, 1997; Jenkins et al., 1998; McGrath, 1984; Milkovich \& Newman, 1999; Wageman \& Baker, 1997). Over the years, studies on teams have progressed from research conducted within experimental settings using largely static group compositions (Peters, Chassie, Lindholm, O'Connor \& Kline, 1982), to studies based in field settings (Cummings, 2004; Gladstein, 1984). More recent research has incorporated the effects of the environment and team composition (Ancona \& Caldwell, 1992; Kouchaki, Okhuysen, Waller \& Tajeddin, 2012) as well as the incorporation of temporal effects in team studies (Marks, Mathieu, \& Zaccaro, 2001; Mohammed \& Nadkarni, 2011). Some research has shown that the outputs of work-team members can be influenced through the use of individual incentive rewards, and that group outputs can be influenced through the use of collective incentive rewards systems (Allen, Sargent \& Bradley, 2003; Condly, Clark \& Stolovitch, 2003; Wageman, 1995). The incorporation of these variables in studies has improved the understanding of the complexity of team functioning.

Several theoretical foundations drive the approaches to compensation and performance, the most prominent of these being individual motivation. Motivation theories can be broken down into three categories: intrinsic motivation theories such as expectancy theory; extrinsic motivation theories such as reinforcement theory (Komaki, Coombs, \& Schepman, 1996); and interactive factor theories such as social and information processing theories (Milkovich \& Newman, 1999) which focus largely on internally-driven derivations of performance outcomes. Expectancy theory is premised on the notion that people are inclined to link their efforts to particular expectations of reward or performance outcomes.

Proponents for the use of financial incentives associate performance improvements with their use via the reinforcement of "desired behaviours" in employees (Jenkins et al., 1998). Some employers successfully use financial incentives to reward positive "marginal" productivity variances of employees and to reduce the costs associated with dysfunctional behaviours of employees (Abelson \& Baysinger, 1984; Jenkins et al., 1998). In a quantitative meta-review of 39 studies on the relationship between financial incentives and performance, Jenkins et al. (1998) found that, although financial incentives were somewhat associated with increased individual performance quantity, this relationship did not exist with performance quality. Research has also shown that to employees, in addition to their monetary value, incentives are also perceived as a source of recognition and status (Steer, Porter \& Bigley, 1996; Jenkins et al., 1998). However, other researchers have argued the negative effects of financial incentives where the incentives appear to reduce intrinsic motivation (Eisenberger \& Cameron, 1996; Kohn, 1993), the selfdetermination of employees (Deci \& Ryan, 1985) and desirable risk-taking behaviours of the employees (Jenkins et al., 1998).

Various studies have been carried out on the use of incentives within the team structure (Barnes, et al., 2011; Beersma et al., 2003; Shaw, Gupta \& Delery, 2002) often with contradictory findings. Wageman and Baker (1997) found that, while incentives were important to performance, the effects were linked to task interdependence, which affected cooperation within the team. Beersma et al. (2003) investigated the intervening roles of task dimension, team composition and individual performance levels and found that a competitive (individual) reward structure enhanced the task dimension of speed, while a cooperation (group) reward structure enhanced the task dimension of accuracy. However, in a meta-study on the effects of incentives on workplace performance, Condly et al. (2003) found that team incentives were more highly associated with performance outcomes as opposed to individual incentives and that both quantity and quality dimensions of performance were positively correlated with incentives. 
Hybrid or interdependent incentives represent any combination of individual- and group- based incentives which organisations can employ, depending on the types of teams present and the levels and types of interdependence present within the team. These and many other intervening variables such as task structure and reward structures (Wageman \& Baker, 1997; Crawford \& LePine, 2013) and autonomy preferences (Wageman, 1995; Wagner, et al., 2012) make the structuring of incentive programs highly complex. A number of researchers (Barnes et al., 2011; Beersma et al., 2003; Shaw et al., 2002) advocate the use of hybrid incentive schemes as the ideal mix to use within the team structure, as hybrids provide the best combination of the benefits accruing from individually motivated effort and group-based extrinsic effects and reinforcement (DeMatteo, Eby, \& Sundstrom, 1998; Kozlowski \& Ilgen, 2006). However, hybrid incentives were also shown to present their own difficulties, most prominent of which is the potential to increase social loafing and the "free-rider effect" (Barnes et al., 2011; Karau \& Williams, 1993).

The literature reveals wide support for the role of work teams in performance improvement within organisational settings (Guzzo \& Dickson, 1996; Stewart, 2006; 2010). There exists empirical support for the roles of interdependent rewards as an important intervening variable in the relationships between work teams and performance (Johnson \& Johnson, 2005; Wageman \& Baker, 1997). Theoretical support for the foundations of these inter-relationships is to be found within the seminal goal interdependence theory of Deutsch (1949) of cooperation and independence categorised situations which, when structured in one way lead to cooperation, while when structured in another, lead to competitive behaviour. Empirical research has also demonstrated the indirect, but positive impact of pay incentives on work team performance. The indirect effects of pay incentives on performance have been shown conceptually and empirically to be mediated by intrinsic and extrinsic motivation (Barnes et al., 2011; Jenkins et al., 1998; Wagner et al., 2012).

\section{Research objectives}

The use of pay incentives is ubiquitous in practice. Although the effects of incentives in support of performance improvements have been shown in teams, the literature does not give adequate empirical evidence in longitudinal field studies which investigate the following questions: 1) do combinations of hybrid and direct incentives lead to performance improvements in work teams in terms of speed and accuracy; 2) if there is improvement in performance within these work teams and if so, is this performance sustainable? Finding answers to these questions are the objectives of this study which are further developed into hypotheses in the methodology section. Using an interrupted time-series design, the study investigated performance improvement sustainability within teams based on quantitative analysis of three measures of individual tellers' performance. This study set out to examine the effects of using incentives to enhance team performance through the alignment of overall team goals by using a combination of individual team member pay incentives based on their own performance and a hybrid incentive pay structure for team supervisors based on a combination of their own and their team members' individual performance. Therefore the research sought to determine the effects on team member performance over time, of introducing a combination of individual pay incentives and hybrid pay incentives for supervisors. The research was designed to compare and explain changes in individual team members' performance measures over the duration of the study.

\section{Method}

The research used an interrupted time-series design. It is classified as quasi-experimental research (Huysamen, 2001) as an intervention was introduced in a field setting without laboratory controls. In line with recommendations for studies with a longitudinal design (Ployhart \& Vandenberg, 2010) baseline data was collected for tellers for a period of six months prior to the intervention, which was the introduction of teams and hybrid pay incentives for team supervisors. Following the introduction of this intervention, daily performance measures for all the tellers were tracked and 
accumulated monthly for an additional period of 18 months, so that in all, 24 months' data was collected and analysed.

The study involved the individual daily tracking of volume, speed and accuracy measures of the deposit-processing performance of all 480 semi-skilled tellers (the population) who worked for a firm in bulk-cash-processing centres. These are dedicated cash deposit handling sites, designed to cater for businesses which have large value cash deposits. This study was conducted in 19 such depots located in various geographical locations around South Africa. Approximately 70 per cent of the tellers were permanent employees who qualified individually to receive pay incentives for reaching target performance levels in terms of volumes, speed and accuracy of deposits processed (the other tellers were contractors and did not qualify for this direct incentive). The total number of tellers (both permanent and contract) who remained for the duration of the study was 82 (designated the sample) and thus only their data was used for data analysis.

In the intervention, approximately six tellers (a mix of contract and permanent tellers) and one supervisor were assigned to a team, based on the historical performance of the tellers, as a means to achieve comparable team composition. The teams had a moderate level of task interdependence. In addition, a hybrid pay incentive structure was introduced for supervisors whereby 60 per cent of their pay incentive bonus was based on the performance ratings of the individual tellers in their teams, while the remainder was derived from the ratings that the tellers within teams gave of their own supervisors. The allocation of tellers and supervisors into teams where the supervisor received a hybrid incentive (i.e. a pay incentive based on components of both individual effort and group effort) was designed to achieve better goal alignment within the team in the hope of achieving sustainable improvements in the performance of individuals within the teams.

Data on the number of deposits, the deposit value processed, and the time taken by the teller to process each deposit was collected and stored electronically. In addition, a journal of the number of errors made by each teller when processing each deposit was logged on the system to determine their levels of accuracy. All the collected data for the 24- month period of the study was processed at monthly intervals to calculate the volume and speed of processing cash deposits and the accuracy with which deposits were counted. This data was aggregated into four periods of six months each by calculating the mean value across the values that were present. The four periods are described as follows: Time 1 covered six months before the intervention during which teams and hybrid incentives for supervisors were introduced, with this time period serving as a baseline reading prior to the intervention; Time 2 covered the period 1-6 months post intervention; Time 3 was 7-12 months post intervention; and Time 4 was 13-18 months post intervention.

The allocation of tellers and supervisors into teams was expected to create greater structural interdependency and boundaries for each team, resulting in an improvement in the performance variables being measured. Accordingly, improvements were expected in the performance measures of speed, volume and accuracy of deposit processing by both regular and contract tellers. It was postulated that, motivated by the hybrid pay incentive structure, supervisors would try to earn maximum pay incentives by attempting to maximise the individual tellers' performances by "stretching" teller effort for maximum performance. Hybrid pay incentives for supervisors were also likely to encourage intra-team support, and improved coordination efforts by supervisors towards their tellers.

\section{Research hypotheses}

The introduction of the intervention was expected to result in increases in the average monthly speed with which deposits were processed, the volumes of deposits processed and the accuracy of processing. These improvements were expected to be consistent for all tellers within the teams, regardless of their employment contract which determined whether or not they received individual bonuses, based on the overriding influence of the supervisor, and the influence of the hybrid pay incentives earned by the supervisor. The following research hypotheses were advanced, based on the literature previously discussed and the research design: 
$\boldsymbol{H}_{1}$ : The average number of deposits processed per unit time per teller (speed) will show an improvement from six months before the introduction of the intervention to 18 months following the introduction of the intervention.

$\boldsymbol{H}_{2}$ : The average number of deposits processed (volumes) will show an improvement from six months before the introduction of the intervention to 18 months following the introduction of the intervention.

$\boldsymbol{H}_{3}$ : The average number of errors (accuracy) will show an improvement from six months before the introduction of the intervention to 18 months following the introduction of the intervention.

\section{Data analysis}

The main technique used for testing the hypotheses was repeated measures analysis of variance (ANOVA), computed using Statistica software v12 ${ }^{\circledR}$ (StatSoft). The significance level used in this study is .05 . In the data preparation phase, the extremely skewed nature of the speed measure was addressed firstly by removing outliers using the Grubbs test, and thereafter applying a square root transformation to achieve an approximately normal score distribution. Scatterplots were used to check the data set for the linearity assumption of the relations. Furthermore, missing monthly data points were accommodated by changing the unit of analysis from 24 monthly values per teller to four six-monthly values per teller (Time periods 1-4 as described previously) wherein the value within a six-month time period was the mean of the values over the six months in that period per teller. Violations of the sphericity assumption of the repeated measures test, as shown by significant values on Mauchly's test, were addressed by using the Greenhouse-Geiser technique which uses conservative estimations of the degrees of freedom to interpret significance levels and partial $\eta^{2}$ effect sizes (Field, 2013). Finally, the more robust multivariate analysis method using Pillai's trace criterion was used to confirm the Greenhouse-Geiser adjusted univariate test results, with post hoc tests and mean plots used to evaluate the significance and direction of the means over time.

\section{Results}

Hypotheses 1-3 were designed to test improvement after the intervention over time in three measures of performance of all tellers, irrespective of their employment status (permanent or contracted).

\section{Testing the employment status (individual teller incentives) effect}

The underlying assumptions in testing these hypotheses were that there would be no significant employment status effect (i.e. main effect) and that the effect of the intervention of teams and hybrid supervisor incentives on teller performance would not differ depending on whether the tellers were getting individual incentives or not (i.e. no interaction effect). The assumption of a non-significant employment status main effect was supported by non-significant between subjects $\mathrm{F}$ ratios with $p$ values of .19, .92 and .17 and low effect sizes ( 12 ranging from .00 to .02) for speed, volume and accuracy respectively. The assumption of non-significant interaction effects was supported both by the Greenhouse-Geiser adjusted univariate tests and the multivariate test using Pillai's trace criterion, with Greenhouse-Geiser within subjects adjusted $p$ values for speed, volume and accuracy of $.47, .31$ and .53 , and $p$ values for Pillai's Trace of $.43, .12$ and .29 respectively. Thus no differences were found in how the intervention, described above, affected the two types of tellers. Thus the underlying assumptions were supported. This in itself is a major finding.

\section{Effects of introduction of teams and hybrid incentives for supervisors}

The results of the ANOVAs are shown in Table 1, presented as a summary of the tests of Hypotheses 1-3, omitting main and interaction effects as discussed above.

As shown in Table 1, both the Greenhouse-Geiser adjusted univariate tests and the multivariate test using Pillai's trace criterion are significant $(p<.001)$ for testing changes in the speed, volume 
and accuracy means over the four time periods. Moreover the effect sizes for these tests are moderate to high with values for partial $\eta^{2}$ ranging from $\eta_{p}{ }^{2}=.18$ to .47 for the adjusted repeated measures ANOVA results, and $\eta_{p}{ }^{2}=.32$ to .64 for the multivariate ANOVA results. This means that between 18 per cent and 47 per cent of the variance in the performance indicators considered separately, or between 32 per cent and 64 per cent of the variance in the performance indicators considered jointly, are explained by changes over the four time periods.

Table 1

Tests of hypotheses of changes in teller performance measures over 24 months

\begin{tabular}{|c|c|c|c|c|c|c|c|c|c|c|c|}
\hline \multirow{3}{*}{$\begin{array}{l}\text { Performance } \\
\text { indicators }\end{array}$} & \multirow{2}{*}{\multicolumn{4}{|c|}{$\begin{array}{c}\text { Tests of within-subjects effects } \\
\text { Greenhouse-Geisser }\end{array}$}} & \multirow{2}{*}{\multicolumn{3}{|c|}{$\begin{array}{l}\text { Test of repeated measures } \\
\text { assumption } \\
\text { Mauchly's test of } \\
\text { Sphericity (df }=5 \text { ) }\end{array}$}} & \multirow{2}{*}{\multicolumn{4}{|c|}{$\begin{array}{l}\text { Multivariate tests } \\
\text { Pillai's Trace }\end{array}$}} \\
\hline & & & & & & & & & & & \\
\hline & $\mathbf{F}$ & df & $p$ & $\eta_{p}^{2}$ & $\begin{array}{c}\text { Mauchly's } \\
\text { W }\end{array}$ & $p$ & $\begin{array}{l}\text { Green } \\
\text { house } \\
\text { Geisser } \varepsilon\end{array}$ & $F$ & df & $p$ & $\eta_{p}^{2}$ \\
\hline Speed & 17.3 & $\begin{array}{r}2.49 \\
184.01 \\
\end{array}$ & $<.001$ & .19 & 0.69 & $<.001$ & .83 & 11.54 & $3 ; 72$ & $<.001$ & .32 \\
\hline Volume & 17.8 & $\begin{array}{r}2.20 \\
178.30 \\
\end{array}$ & $<.001$ & .18 & 0.58 & $<.001$ & .73 & 14.41 & $3 ; 79$ & $<.001$ & .35 \\
\hline Accuracy & 72.7 & $\begin{array}{r}1.73 \\
140.39\end{array}$ & $<.001$ & .47 & 0.33 & $<.001$ & .58 & 45.91 & $3 ; 79$ & $<.001$ & .64 \\
\hline
\end{tabular}

Furthermore, Bonferroni post hoc comparisons of the mean differences from Time 1 to Time 4 (i.e. from six months prior to the team intervention to 18 months after) showed significant differences $(p<.001$ throughout) in the direction of increased productivity for the speed, volume and accuracy measures. To support these findings, Figures 1-3 show the mean values and 95 per cent confidence intervals for the three performance indicators, shown on the vertical axes, over the four time periods, shown on the horizontal axes, corresponding to Hypotheses 1-3. Speed was measured in seconds. Volumes and accuracy were statistically mapped onto rating scales with a maximum value of 4 .

Figure 1 is the means plot for speed of deposit processing over the four time periods, operationalised as the average time taken to process a single deposit. This graph shows a decrease in time, i.e. an improvement in the average time taken to process a single deposit over the first three time periods, with a marginal but non-significant negative change from Time 3 to Time 4 ( $p=.99$ ). Figures 2 and 3 respectively are means plots for volumes and accuracy ratings over the four time periods, and both show a monotonic trend in performance improvement over the four time periods. In summary, in all three measures of performance, the post hoc mean comparisons between Times 1 and 4 are significant, and the changes in these mean values are in the direction of increased productivity. Thus the substantial time effect, together with the increases in the three productivity measures over time, are all evidence for supporting the three hypotheses of the research.

Figure 1

Means plot for average time per envelope processed

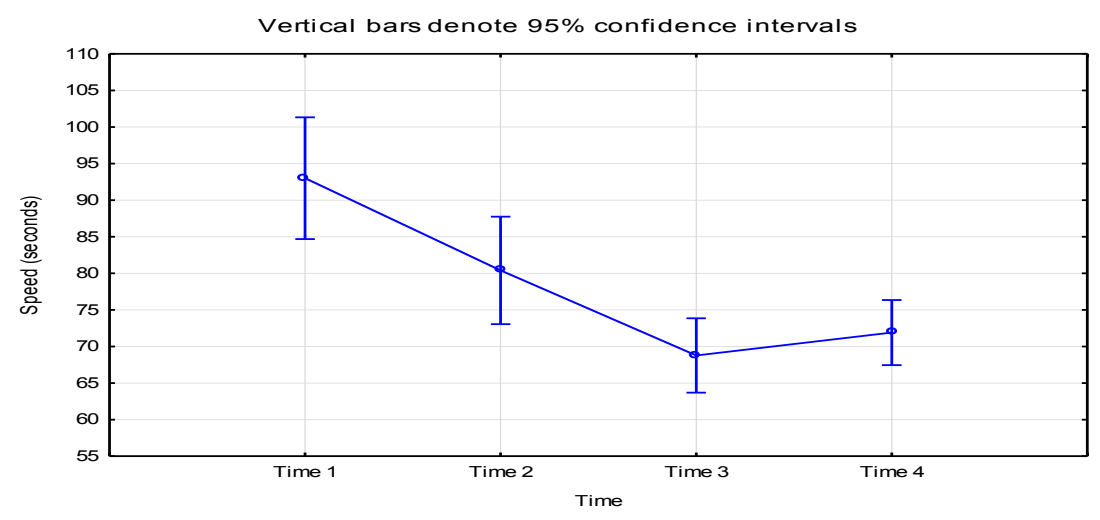


Figure 2

Means plot of volume ratings

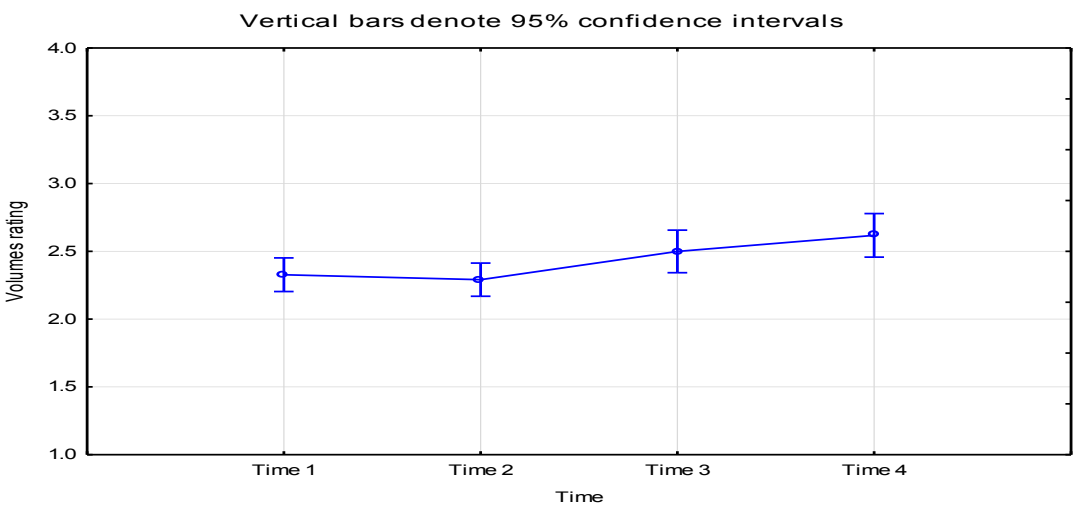

Figure 3

Means plot for accuracy ratings

Vertical bars denote $95 \%$ confidence intervals

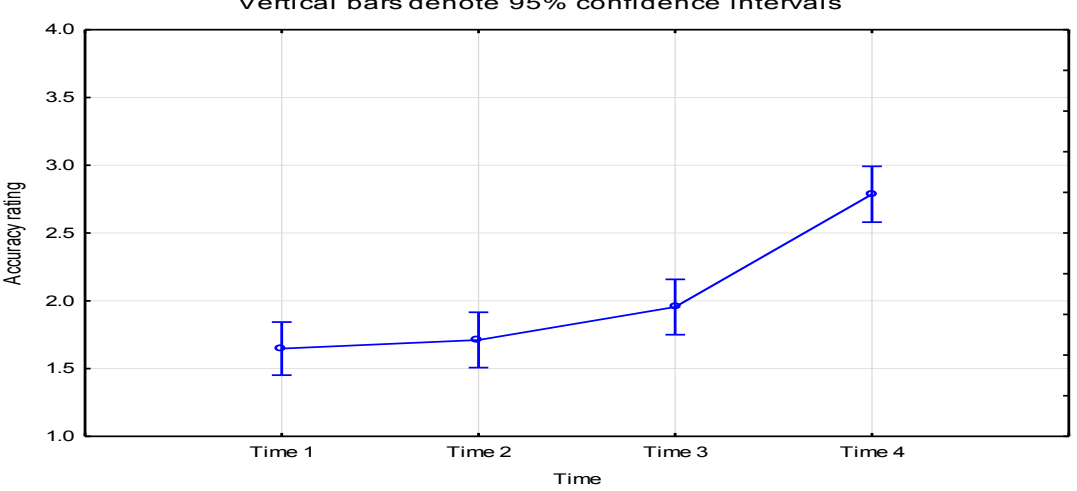

\section{Discussion}

The basis for this study was that as the use of pay incentives is ubiquitous in practice, it is in the interests of both practitioners and scholars to examine more fully some of the effects of these incentives on performance of team members over time in a field setting. Thus the research was designed to compare and explain changes in individual team members' performance measures for the duration of the study after being put into teams, and their immediate supervisors' being given a hybrid incentive scheme, dependent on both their own and their team members' individual performances.

The first major finding was that the effect of the hybrid incentive on the team supervisors affected the performance of both employees on permanent employment contracts who received individual incentives and employees on renewable fixed-term contracts, who received no such incentives, in the same way. There was no significant difference between the two groups' responses when these individuals worked within a combined team structure in which the team supervisor received hybrid pay incentives. Both types of tellers' performance on the three variables increased to the same extent. This generalisability of hybrid incentives has never previously been demonstrated in the research literature (Jenkins et al.,1998; Johnson \& Johnson, 2005; Wageman \& Baker, 1997; Condly et al., 2003). This overall positive main effect of team allocation and giving supervisors incentives based on individual team members' performance adds to the field of knowledge in the remuneration field. 
The second major finding was that within the setting for this study allocating tellers into teams and providing hybrid pay incentives for team supervisors affected teller performance positively, as measured by improvement in the three measures of teller performance: speed, volume and accuracy of deposit processing. Speed and volume were proxy for performance quantity and accuracy for performance quality. Complex tasks have been shown by Beersma et al. (2003) to require a combination of speed and accuracy but Elliot, Helsen and Chua (2001) have shown that there is a trade-off between speed and accuracy when performing these tasks. In their meta-study, Jenkins et al. (1998) showed that incentives appear to have different influences on the degree of emphasis on quality and quantity, i.e. speed and accuracy in teams. However Condly et al. (2003), following a review of studies on the effects of incentives on team performance, found that incentives positively affected both task speed and task accuracy. This study's findings concur with Condly et al. (2003) and extend his findings by showing that the allocation of both individually incentivised and non-incentivised tellers to teams with supervisors who had hybrid pay incentives was associated with improvements in both the quality (accuracy) and the speed of task accomplishment (speed of processing deposits and volumes processed). The trade-off did not occur for both types of tellers. This makes a contribution to the literature.

The third major finding was that all three hypotheses were supported. The positive improvements in all three measures of performance were sustained for eighteen months after the introduction of the intervention. This study found consistent and sustainable performance improvement associated with the structural interdependence conferred by the work-team structure and supervisor hybrid pay incentives. Studies by Cohen and Bailey (1997), Stewart and Barrick (2000), Wageman (1995) and Wageman and Baker (1997) have all shown that task types and the design of tasks in teams affect team performance. The structure of the incentive program itself (e.g. hybrid versus individual incentives) has been shown (Wageman \& Baker, 1997; Jenkins et al., 1998) to act as an intervening variable between incentives and performance. The findings of this study support and extend these studies. The duration of the study, the field setting, the large sample size and the number of variables measured enhance the validity and contribution of these findings.

\section{Conclusion}

The structuring of incentive programs is highly complex and has thus been the subject of much research in the compensation field (Barnes et al., 2011; Beersma et al., 2003; Shaw et al., 2002). This study offers insights on the effects of hybrid pay incentives, how incentives can be structured and the consequences of this structuring within work-teams. The study shows that placing employees into teams with moderate levels of task interdependence and simultaneously putting into place hybrid pay incentives for the team supervisors are useful levers to encourage sustained improvements in employee performance, irrespective of whether they are individually incentivised or not.

In South Africa, effectively incentivised self-regulating work-teams present an opportunity for increased productivity within labour-intensive settings. These teams provide a platform to reduce the levels of senior management oversight required. For remuneration practitioners, this study offers an opportunity to consider the re-design and/or the introduction of incentivised team-based remuneration structures which may reduce the protracted annual wage negotiations that are common in various sectors of the South African economy.

\section{Limitations and recommendations}

The limitation of this study to teams within bulk-cash processing centres in South Africa affects the ability to generalise these findings, which in turn offers an opportunity to replicate the study on work-teams in other industry settings. There is an abundance of task inter-dependent work-teams in manufacturing and educational settings (Johnson \& Johnson, 2005) and a wide variety of forms 
which work-teams can take (such as quality circles, research teams). These offer a wonderful opportunity to replicate the findings from this research in other settings.

\section{References}

ABELSON, M.A. \& BAYSINGER, B.D. 1984. Optimal and dysfunctional turnover: Toward an organizational-level model. Academy of Management Review, 9:331-341. Available at: doi: 10.5465/AMR. 1984.4277675

ALLEN, N.J. \& HECHT, T.D. 2004. The 'romance of teams': Toward an understanding of its psychological underpinnings and implications. Journal of Occupational and Organizational Psychology, 77:439-461. Available at: doi: 10.1348/0963179042596469.

ALLEN, B.L., SARGENT, L.D. \& BRADLEY, L.M. 2003. Differential effects of task and reward interdependence on perceived helping behavior, effort, and group performance. Small Group Research, 34: 716-740. Available at: doi: 10.1177/1046496403257615.

ANCONA, D.G. \& CALDWELL, D.F. 1992. Bridging the boundary: External activity and performance in organizational teams. Administrative Science Quarterly, 37:634-665. Available at: doi: 2393475.

BANKER, R.D., FIELD, J. M., SCHROEDER, R. G. \& SINHA, K. K. 1996. Impact of work teams on manufacturing performance: A longitudinal study. Academy of Management Journal, 39:867-890. Available at: doi: $10.2307 / 256715$.

BARNES, C.M., HOLLENBECK, J.R., JUNDT, D.K., DERUE, D.S. \& HARMON, S. J. 2011. Mixing individual incentives and group incentives: Best of both worlds or social dilemma? Journal of Management, 37, 1611-1635. doi: 10.1177/0149206309360845.

BEERSMA, B., HOLLENBECK, J.R., HUMPHREY, S.E., MOON, H., CONLON, D.E. \& ILGEN, D.R. 2003. Cooperation, competition, and team performance: Toward a contingency approach. Academy of Management Journal, 46:572-90. doi: 10.2307/30040650.

BELL, S.T. \& MARENTETTE, B.J. 2011. Team viability for long-term and ongoing organizational teams. Organizational Psychology Review, 1:275-292. Available at: doi: 10.1177/2041386611405876.

CAMPION, M.A., MEDSKER, G.J. \& HIGGS, A.C. 1993. Relations between group work characteristics and effectiveness: Implications for designing effective work groups. Personnel Psychology, 46:823-850. Available at: doi: 10.1111/j.1744-6570.1993.tb01571.x.

COFF, R.W. \& KRYSCYNSKI, D. 2011. Drilling for microfoundations of human capital-based competitive advantages. Journal of Management, 37:1429-1443. Available at: doi: 10.1177/0149206310397772.

COHEN, S.G. \& BAILEY, D.E. 1997. What makes teams work: Group effectiveness research from the shop floor to the executive suite. Journal of Management, 23:239-290. Available at: doi: 10.1177/ 014920639702300303.

CONDLY, S.J., CLARK, R.E. \& STOLOVITCH, H. D. 2003. The effects of incentives on workplace performance: A meta-analytic review of research studies. Performance Improvement Quarterly, 18:46-63. Available at: doi: 10.1111/j.1937-8327.2003.tb00287.x.

CRAWFORD, E.R. \& LEPINE, J.A. 2013. A configural theory of team processes: Accounting for the structure of taskwork and teamwork. Academy of Management Review, 38:32-48. Available at: doi: 10.5465/ amr.2011.0206.

CROOK, T.R., TODD, S.Y., COMBS, J.G., WOEHR, D.J. \& KETCHEN, D.J. 2011. Does human capital matter? A meta-analysis of the relationship between human capital and firm performance. Journal of Applied Psychology, 96:443-456. Available at: doi: 10.1037/a0022147.

CUMMINGS, J.N. 2004. Work groups, structural diversity, and knowledge sharing in a global organization. Management Science, 50:352-364. Available at: doi: 10.1287/mnsc.1030.0134.

DECI, E.L. \& RYAN, R.M. 1985. Intrinsic motivation and self determination in human behavior. New York: Plenum.

DEMATTEO, J.S., EBY, L.T. \& SUNDSTROM, E. 1998. Team-based rewards: Current empirical evidence and directions for future research. Research in Organizational Behavior, 20:141-183.

DEUTSCH, M. 1949. A theory of cooperation and competition. Human Relations, 2(2):129-151.

DEVINE, D.J., CLAYTON, L.D., PHILIPS, J.L., DUNFORD, B.B. \& MELNER, S.B. 1999. Teams in organizations. Small Group Research, 30:678-711. Available at: doi: 10.1177/104649649903000602. 
DICKINSON, T.L. \& MCINTYRE, R.M. 1997. A conceptual framework for teamwork measurement. In M.T. Brannick, E. Salas \& C. Prince (eds.) Team performance and measurement: Theory, methods, and applications (pp. 19-43). Mahwah, NJ, USA.

EISENBERGER, R. \& CAMERON, J. 1996. Detrimental effects of rewards: Reality or myth? American Psychologist, 51:1153-1166. Available at: doi: 10.1037/0003-066X.51.11.1153.

ELLIOTT, D., HELSEN, W.F. \& CHUA, R. 2001. A century later: Woodworth's (1899) two-component model of goal-directed aiming. Psychological Bulletin, 127:342-357. Available at: doi: 10.1037/00332909.127.3.342.

FIELD, A.P. 2013. Discovering statistics using IBM SPSS statistics ( $4^{\text {th }}$ ed.) London: Sage Publications. GLADSTEIN, D.L. 1984. Groups in context: A model of task group effectiveness. Administrative Science Quarterly, 29, 499-517. Available at: doi: 2392936.

GUZZO, R.A. \& DICKSON, M.W. 1996. Teams in organizations: Recent research on performance and effectiveness. Annual Review of Psychology, 47:307-338. Available at: doi: 10.1146/annurev.psych.47.1.307. HOLLENBECK, J.R., BEERSMA, B. \& SCHOUTEN, M.E. 2012. Beyond team types and taxonomies: A dimensional scaling conceptualization for team description. Academy of Management Review, 37:82-106. Available at: doi: 10.5465/amr.2010.0181.

HUYSAMEN, G.K. 2001. Methodology for the social and behavioural sciences. Oxford Universtiy Press: Cape Town.

JENKINS, G.D., MITRA, A., GUPTA, N. \& SHAW, J.D. 1998. Are financial incentives related to performance? A meta-analytic review of empirical research. Journal of Applied Psychology, 83:777-787. Available at: doi: 10.1037/0021-9010.83.5.777.

JOHNSON, D.W. \& JOHNSON, R.T. 2005. New developments in social interdependence theory. Genetic, Social, and General Psychology Monographs, 131. Available at: doi: 10.3200/MONO.131.4.285-358.

KARAU, S.J. \& WILLIAMS, K.D. 1993. Social loafing: A meta-analytic review and theoretical integration. Journal of Personality and Social Psychology, 65, 681-706. Available at: doi: 10.1037/0022-3514.65.4.681. KOHN, A. 1993. Why incentives plans cannot work. Harvard Business Review. September/October:54-63.

KOMAKI, J.L., COOMBS, T. \& SCHEPMAN, S. 1996. Motivational implications of reinforcement theory. Published in R.M. Steers, L.W. Porter, \& G.A. Bigley (eds.) Motivation and leadership at work (pp. 34-52). New York: McGraw-Hill.

KOUCHAKI, M., OKHUYSEN, G.A., WALLER, M.J. \& TAJEDDIN, G. 2012. The treatment of the relationship between groups and their environments: A review and critical examination of common assumptions in research. Group \& Organization Management, 37:171-203. Available at: doi: $10.1177 / 1059601112443850$.

KOZLOWSKI, S.W.J. \& ILGEN, D.R. 2006. Enhancing the effectiveness of work groups and teams. Psychological Science in the Public Interest, 7:77-124. Available at: doi: 40062361.

LEPINE, J.A; PICCOLO, R.F., JACKSON, C.L., MATHIEU, J.E. \& SAUL, J.R. 2008 A meta-analysis of teamwork processes: Tests of a multidimensional model and relationships with team effectiveness criteria. Personnel Psychology, 61(2):273-307. Available at: S

MARKS, M.A., MATHIEU, J.E. \& ZACCARO, S.J. 2001. A temporally based framework and taxonomy of team processes. Academy of Management Review, 26:356-376. Available at: doi: 10.5465/ AMR.2001.4845785.

MARUYAMA, K. \& EILLIOT, J. A. 2012. The competition-performance relation: A meta-analytic review and test of the opposing processes model of competition and performance. Psychological Bulletin, 138(6): 1035-1070. Available: doi: 10.1037/a0028324

MATHIEU, J., MAYNARD, M.T., RAPP, T. \& GILSON, L. 2008. Team effectiveness 1997-2007: A review of recent advancements and a glimpse into the future. Journal of Management, 34:410. Available at: doi: $10.1177 / 0149206308316061$

MATHIEU, J.E., TANNENBAUM, S.I., DONSBACH, J.S. \& ALLIGER, G.M. 2014. A review and integration of team composition models: Moving toward a dynamic and temporal framework. Journal of Management, 40:130-160. Available at: doi: 10.1177/0149206313503014.

MCGRATH, J.E. 1984. Groups: Interaction and performance. Englewood Cliffs, NJ: Prentice-Hall. 
MESSERSMITH, J.G., PATEL, C.P. \& LEPAK, D.P. 2011. Unlocking the black box: Exploring the link between high-performance work systems and performance. Journal of Applied Psychology, 96:1105-1118. Available at: doi: $10.1037 / \mathrm{a} 0024710$.

MILKOVICH, G.T. \& NEWMAN, J.M. 1999. Compensation. Boston: Irwin.

MOHAMMED, S. \& NADKARNI, S. 2011. Temporal diversity and team performance: The moderating role of team temporal leadership. Academy of Management Journal, 54:489-508. Available at: doi: 10.5465/AMJ.2011.61967991.

PETERS, L.H., CHASSIE, M.B., LINDHOLM, H.R., O’CONNOR, E.J. \& KLINE, C. R. 1982. The joint influence of situational constraints and goal setting on performance and affective outcomes. Journal of Management, 8:7-20. Available at: doi: 10.1177/014920638200800201.

PLOYHART, R.E. \& VANDENBERG, R.J. 2010. Longitudinal research: The theory, design and analysis of change. Journal of Management, 36:94-120. Available at: doi: 10.1177/0149206309352110.

PLOYHART, R.E., WEEKLEY, J.A. \& RAMSEY, J. 2009. The consequences of human resource stocks and flows: A longitudinal examination of unit service orientation and unit effectiveness. Academy of Management Journal, 52(5):996-1015. Available at: doi: 10.5465/AMJ.2009.44635041.

SHAW, J.D., GUPTA, N. \& DELERY, J.E. 2002. Pay dispersion and workforce performance: Moderating effects of incentives and interdependence. Strategic Management Journal, 23:491-512. Available at: doi: $10.1002 /$ smj.235.

SHAW, J.D., PARK, T. \& KIM, E. 2013. A resource-based perspective on human capital losses, HRM investments, and organizational performance. Strategic Management Journal, 34:572-589. Available at: doi: $10.1002 / \mathrm{smj} .2025$.

SONNENTAG, S. 2012. Time in organizational research: Catching up on a long neglected topic in order to improve theory. Organizational Psychology Review, 2:361-368. Available at: doi: 10.1177/ 2041386612442079.

STATISTICA 12. StatSoft Inc. $1984-2013$.

STEERS, R.M., PORTER, L.W. \& BIGLEY, G.A. 1996. Motivation and leadership at work. New York: McGraw-Hill.

STEWART, G.L. 2010. The past twenty years: Teams research is alive and well at the Journal of Management. Journal of Management, 36:801. Available at: doi: 10.1177/0149206310371512.

STEWART, G.L. 2006. A meta-analytic review of relationships between team design features and team performance. Journal of Management, 32:29-54. Available at: doi: 10.1177/0149206305277792.

STEWART, G.L. \& BARRICK, M.R. 2000. Team structure and performance: Assessing the mediating role of intrateam process and the moderating role of task type. Academy of Management Journal, 43:135-148. Available at: doi: 10.2307/1556372.

VIETOR, R.H.K. 2007. How countries compete: Strategy, structure, and government in the global economy. Boston: Harvard Business School Press.

WAGEMAN, R. 1995. Interdependence and group effectiveness. Administrative Science Quarterly, 40:145180. Available at: doi: 2393703.

WAGEMAN, R. \& BAKER, G. 1997. Incentives and cooperation: The joint effects of task and reward interdependence on group performance. Journal of Organizational Behaviour, 18:139-158. Available at: doi: 10.1002/(SICI)1099-1379(199703)18:2.

WAGNER, J.A., HUMPHREY, S.E., MEYER, C.J. \& HOLLENBECK, J.R. 2012. Individualismcollectivism and team member performance: Another look. Journal of Organizational Behavior, 33:946-963. Available at: doi: 10.1002/job.783.

WORLD ECONOMIC FORUM. 2012. The global competitiveness index 2012-2013. Available at: http://www.weforum.org/reports/global-competitiveness-report-2012-2013 [accessed 2015-11-13]. 